\title{
Estimation of crop water stress in a nectarine orchard using high-resolution imagery from unmanned aerial vehicle (UAV)
}

\author{
$\underline{\text { S. Park }}^{\text {a }}$, A. Nolan ${ }^{\text {a }}$, D. Ryu ${ }^{\text {a }}$, S. Fuentes ${ }^{\text {b }}$, E. Hernandez ${ }^{\text {b }}$, H. Chung ${ }^{\text {c }}$ and M. O'Connell ${ }^{d}$ \\ ${ }^{a}$ Department of Infrastructure Engineering, The University of Melbourne, Parkville, Victoria, Australia \\ ${ }^{b}$ Department of Agriculture and Food Systems, Faculty of Veterinary and Agricultural Sciences, The \\ University of Melbourne, Parkville, Victoria, Australia \\ ${ }^{c}$ Department of Mechanical and Aerospace Engineering, Monash University, Clayton, Victoria, Australia \\ ${ }^{d}$ Department of Economic Development, Jobs, Transport and Resources, Tatura, Victoria, Australia \\ Email: suyoungp@student.unimelb.edu.au
}

\begin{abstract}
Adequate and timely irrigation based on real-time monitoring of crop water status is critical for efficient and sustainable water use. However, detection of water status in large crop fields is not a trivial task as manual inspection can be time consuming and costly. Moreover, the symptoms of water stress are visually detectable only after the crops are already in a significantly water deficient stage. Consequently, capability of monitoring water status in crops on a regular basis could maximize productivity and water use efficiency. As an indicator, the crop water stress index (CWSI) has been widely used to estimate water status in the crop fields. CWSI can be derived from ground-based leaf temperature measurements, however, airborne or UAVborne high-resolution thermal sensing provides a superior platform to cover large regions within a short time window. In this paper, UAV-borne thermal sensing was conducted to map plant water stress and spatial variability in water control and deficit plots over 1 ha of a nectarine orchard at an altitude of $100 \mathrm{~m}$ from ground level. Targets of ground control points (GCPs) were designed to suit the image spatial resolution as well as the visibility in the thermal infrared spectral range. The target was made of aluminium body marked with a black cross, which can be detected as a cool object in the thermal infrared image due to its low emissivity. Thermal infrared images were post-processed to generate single temperature-based orthomosaic image for the entire study field. CWSI map was computed using canopy temperatures at the centre of canopies from the mosaic image. Histogram analysis was used to estimate the lower boundary temperature $\left(\mathrm{T}_{\text {wet }}\right)$, representing the temperature of fully transpiring leaves. The upper boundary temperature $\left(\mathrm{T}_{\text {dry }}\right)$ was determined by air temperature $+6{ }^{\circ} \mathrm{C}$. Ground measurements of midday stem water potential (SWP) and stomatal conductance $\left(\mathrm{g}_{\mathrm{c}}\right)$ were collected concurrently with UAV operation and used to correlate the thermal measurement to crop biophysical parameters. Results showed that CWSI was in good agreement with both SWP and $g_{c}$ with determination coefficients $\left(R^{2}\right)$ of 0.92 and 0.97 , respectively. Thus, remotely estimated CWSI from a UAV platform can play an important role in effective mapping of spatial variability of nectarine water stress and subsequently in optimal management of irrigation.
\end{abstract}

Keywords: $\quad$ Unmanned Aerial Vehicle (UAV), thermal infrared imagery, Crop Water Stress Index (CWSI), canopy temperature, Stem Water Potential (SWP) 


\section{INTRODUCTION}

Undesirable water stress in some crops causes lower levels of quality and yield. Adequate and timely irrigation based on real-time monitoring of water status in crops is highly desired to control quality and yield. As an indicator of crop water status, the Crop Water Stress Index (CWSI) was introduced based on the energy balance (Jackson et al., 1981). In early research, the canopy temperature was measured with handheld infrared thermometers, targeting dominant foliage. However, measuring the representative canopy temperature using a portable infrared thermometer is difficult, especially over large areas featuring heterogeneous biophysical and water stress states (Moran et al., 1994). In addition, ground-based methods are often labor intensive and sometimes impractical when applied to the entire crop area. As the availability of various remote sensing data has dramatically increased in recent years, several investigations on estimating water stress by combining ground measurement and remotely sensed imagery data have been conducted in order to not only apply to larger areas of crops, but also to reduce the complexity of ground measurement and water stress index calculation (Gao, 1996; Leinonen and Jones, 2004; Kim et al., 2011).

Based on remotely estimated CWSI, various studies using both visible and thermal infrared images attempted to calculate the level of crop water stress as a quantitative index (Leinonen and Jones, 2004). For the calculation of the crop temperature separately from soil temperature, the co-registration method utilizing visible and thermal images in ground platforms has been explored (Möller et al., 2007). This methodology enables foliage cover area and the soil surface to be distinguished in the visible image from each other. The foliage cover temperature is calculated in the thermal image, which is co-registered with the visible image that is used to mask out non-leaf material. Despite the advantages of this methodology in measuring the canopy area, it requires time-consuming co-registration post analysis. In order to eliminate the need for visible imagery and to facilitate the calculation of CWSI, a method using only thermal imagery from near ground level has been proposed based on individual histogram analysis per image, in which the histogram of thermal imagery was applied to determine canopy related pixels by statistical and empirical methods (Meron et al., 2010; Rud et al., 2014). An automated version of this methodology was proposed in order to assess effectively vine water status within a short time window (Fuentes et al., 2012). Apart from the thermal images obtained from ground platforms, the unmanned aerial vehicle (UAV) based remote sensing has been developed and research on water stress detection with UAV system has been recently conducted, due to the rising need for economical and high resolution aerial images at large scale (Berni et al., 2009; Zarco-Tejada et al., 2012; Bellvert et al., 2014).

The main objective of this research is to estimate CWSI with reduced field-based measurements and improved efficiency in the UAV-borne estimation. CWSI maps were generated to assess spatial variability of water stress under irrigation control and deficit regimes over a nectarine orchard using high-resolution thermal imagery from a UAV platform. The remotely estimated CWSI was compared with ground measurements of midday stem water potential (SWP) and stomatal conductance $\left(\mathrm{g}_{\mathrm{c}}\right)$, which were used as traditional crop water status parameters.

\section{MATERIALS AND METHODS}

\subsection{Experimental site}

The experiment was carried out at a late maturing stage of nectarine in the Stonefruit Field Laboratory orchard of the Department of Economic Development, Jobs, Transport and Resources (DEDJTR), Tatura, Victoria, Australia $\left(36^{\circ} 26^{\prime} 08^{\prime \prime} \mathrm{S}, 145^{\circ} 16^{\prime} 13^{\prime \prime E}, 114 \mathrm{~m}\right.$ elevation) on the $22^{\text {nd }}$ of February, 2015. The soil is Shepparton fine sandy loam. Nectarine (the Prunus persica (L.) Batsch cv. Autumn Bright) trees were planted in 2014, at a row spacing of $4.5 \mathrm{~m}$ and tree spacing of $1.0 \mathrm{~m}$ in a 0.97 ha orchard (138 x 70 meters). Trees were trained to two canopy systems: central leader with one central vertical trunk and Tatura trellis with one vertical trunk and two arms canopies as Y shaped trees.

For Tatura trellis trees, the canopy dimension of each leader was $1.85 \mathrm{~m}$ tall and $0.5 \mathrm{~m}$ wide. For central leader trees, canopy dimensions of were $2.0 \mathrm{~m}$ tall and $0.8 \mathrm{~m}$ wide. The study site (Figure 1 ) was divided into four experimental plots, where two irrigation treatments were applied as water control and deficit groups (Table 1). Irrigation was applied via water drip lines located along the tree line with a flow rate of $1.6 \mathrm{Lh}^{-1}$ per $0.5 \mathrm{~m}$. The two control plots (and remainder of orchard) were irrigated to meet crop water requirement on a daily basis, where irrigation run-time was decided by a weather-based crop evapotranspiration (ETc) model. 
Two deficit plots were imposed by withholding irrigation by closure of the dripper tap five days prior to the UAV and field data acquisition. Each plot has approximately 20 nectarine trees on average.

\subsection{UAV imagery acquisition}

A thermal Infrared (TIR) camera (A65, FLIR Systems, Inc.) was carried in the multirotor type of UAV system (S900, DJI, Shenzhen, China). The camera spectral range is $7.5-13 \mu \mathrm{m}$ with a resolution of $640 \times 512$ pixels, a focal length of 25 $\mathrm{mm}$, and a field of view of $25^{\circ}(\mathrm{H}) \times 20^{\circ}(\mathrm{V})$. The measurement accuracy of temperature is within $\pm 5^{\circ} \mathrm{C}$. Temperature calibration process was carried out to retrieve more accurate temperatures of surface with a known temperature of a ground target. TIR images were acquired across the entire orchard at near solar noon under clear sky conditions. Targets of ground control points (GCPs) were designed to be both suitable for image spatial resolution and for thermal camera visibility. In particular, the target material was made of aluminium sheet, which works as a cool target in the thermal image due to its low emissivity in the thermal infrared range. Total of 24 GCPs with $60 \times 60 \mathrm{~cm}$ size were deployed in the test field and surveyed using a differential GPS (DGPS) with less $3 \mathrm{~cm}$ accuracy as shown in Figure 1. The flight plan was established at a horizontal speed of $2 \mathrm{~ms}^{-1}$ and an altitude of $90 \mathrm{~m}$ above ground level (AGL), for the consideration of image footprint and overlap for image post-processing. The footprint of a single thermal image was approximately 39.2 $\mathrm{x} 31.3 \mathrm{~m}$, and one pixel ground sample distance (GSD) was $6.12 \mathrm{~cm}$. This GSD enabled clear distinguishment between leaf area and soil. The entire experiment orchard was covered in one flight by 118 thermal images with over $60 \%$ forward and $40 \%$ side overlap. Camera and flight parameters at $90 \mathrm{~m}$ AGL are described in Table 2.

\subsection{Ground data acquisition}

Leaf temperature was measured on the two sample trees for each irrigation treatment using a handheld infrared thermometer (TN410LCE, ZyTemp) within 40 minutes of UAV image acquisition. Stomatal conductance $\left(\mathrm{g}_{\mathrm{c}}, \mathrm{mmol} \mathrm{m} \mathrm{m}^{-2} \mathrm{sec}^{-1}\right)$ was obtained on three fully expanded sunlit leaves per sample tree using a portable photosynthesis system (LI-6400; LI-COR Inc., Lincoln, Nebraska, USA) during midday. Stem water potential ( $\psi_{\text {stem, }}$ $\mathrm{MPa}$ ) was measured on two fully expanded and shaded leaves per sample tree with a Scholander pressure chamber (Model 3000; Soil Moisture Equipment Co., Santa Barbara, CA, USA) during midday. Leaves located on branches near the main

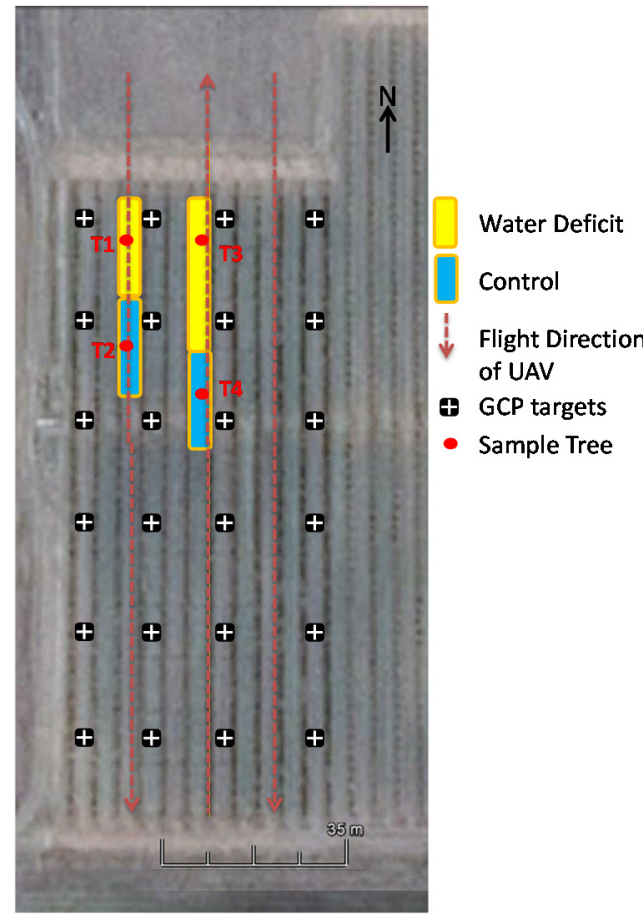

Figure 1. Experimental site (1 ha) in the Stonefruit Field Laboratory orchard. Water deficit plots are presented in yellow, and control plots in blue. T1-T4 represents the sample tree from each treatment. The location of ground control point (GCP) in a black square with a white cross.

Table 1. Descriptions of sample trees.

\begin{tabular}{|c|c|c|c|}
\hline Sample & Crop cultivar & Tree Training & Treatment \\
\hline T1 & Nectarine_Autumn Bright & Central Leader & Deficit \\
\hline T2 & Nectarine_Autumn Bright & Central Leader & Control \\
\hline T3 & Nectarine_Autumn Bright & Tatura Trellis & Deficit \\
\hline T4 & Nectarine_Autumn Bright & Tatura Trellis & Control \\
\hline
\end{tabular}

Table 2. TIR camera specifications on UAV.

\begin{tabular}{|l|r|}
\hline Specifications & TIR image (FLIR A65) \\
\hline Focal Length (mm) & 25 \\
\hline Resolution (pixel) & $640 \times 512$ \\
\hline Thermal Sensitivity & $<0.05^{\circ} \mathrm{C}$ at $30^{\circ} \mathrm{C}$ \\
\hline Accuracy & $\pm 5^{\circ} \mathrm{C}$ \\
\hline Image footprint (m) & $39.2 \times 31.3$ \\
\hline Pixel GSD (cm) & 6.12 \\
\hline Image radiometric resolution (bit) & 14 \\
\hline
\end{tabular}


trunk were covered with an aluminium foil bag for an equilibration period of 15-20 minutes prior to excision and the measurement of water potential. Air temperature for the upper boundary temperature $\left(\mathrm{T}_{\text {dry }}\right)$ was obtained from the nearby $(<300 \mathrm{~m})$ Bureau of Meteorology weather station (No. 081049).

\subsection{Image processing}

TIR images were obtained into 14-bit raw format of signal-based values emitted from the objects. The raw TIR images were processed with Matlab R2014b (Mathworks Inc.) and converted to 14-bit temperaturebased data according to the FLIR Systems' register values. To retrieve accurate temperatures from the raw signal data, the temperature values of calibration targets such as water body, bare soil, and vegetation were measured with a hand-held infrared thermometer concurrently with the UAV operation over the experimental site. Eqs. (1) and (2) are the formulas of one-point calibration for retrieving the adjusted surface temperature provided by FLIR systems (FLIRSystems, 2013).

$$
\begin{aligned}
& O_{\text {adjusted }}=S-\frac{R}{e^{\left(B / T_{\text {known }} \text { in Kelvin }\right)-1}} \\
& T_{\text {adjusted (in Kelvin) }}=\frac{B}{\log \left(\frac{R}{S-O_{\text {adjusted }}}+1\right)}
\end{aligned}
$$

where $\mathrm{S}$ is a 14-bit raw signal value, $\mathrm{T}$ an object temperature, $\mathrm{R}$ a constant for converting flux to temperature derived from Planck's constant h, B a constant derived from Boltzmann's constant and Planck's constant h, $\mathrm{O}$ an offset (signal to radiance). The temperature of the calibration target was used to calculate the adjusted offset parameter $\left(O_{\text {adjusted }}\right)$, and then adjusted temperature was obtained.

The Agisoft PhotoScan software (Agisoft LLC, Russia) was used to perform photogrammetric processing of aerial image triangulation and georeferenced orthomosaic based on the geo-tagged flight log and GCPs. Figure 2 (a) shows the orthomosaic TIR image from UAV, showing the temperature variability of the orchard. Figure 2 (b) shows the features of the two canopy training systems (Central Leader and Tatura Trellis), the shape of GCP, and the differences in pixel temperatures of vegetation and soil area.

(a)
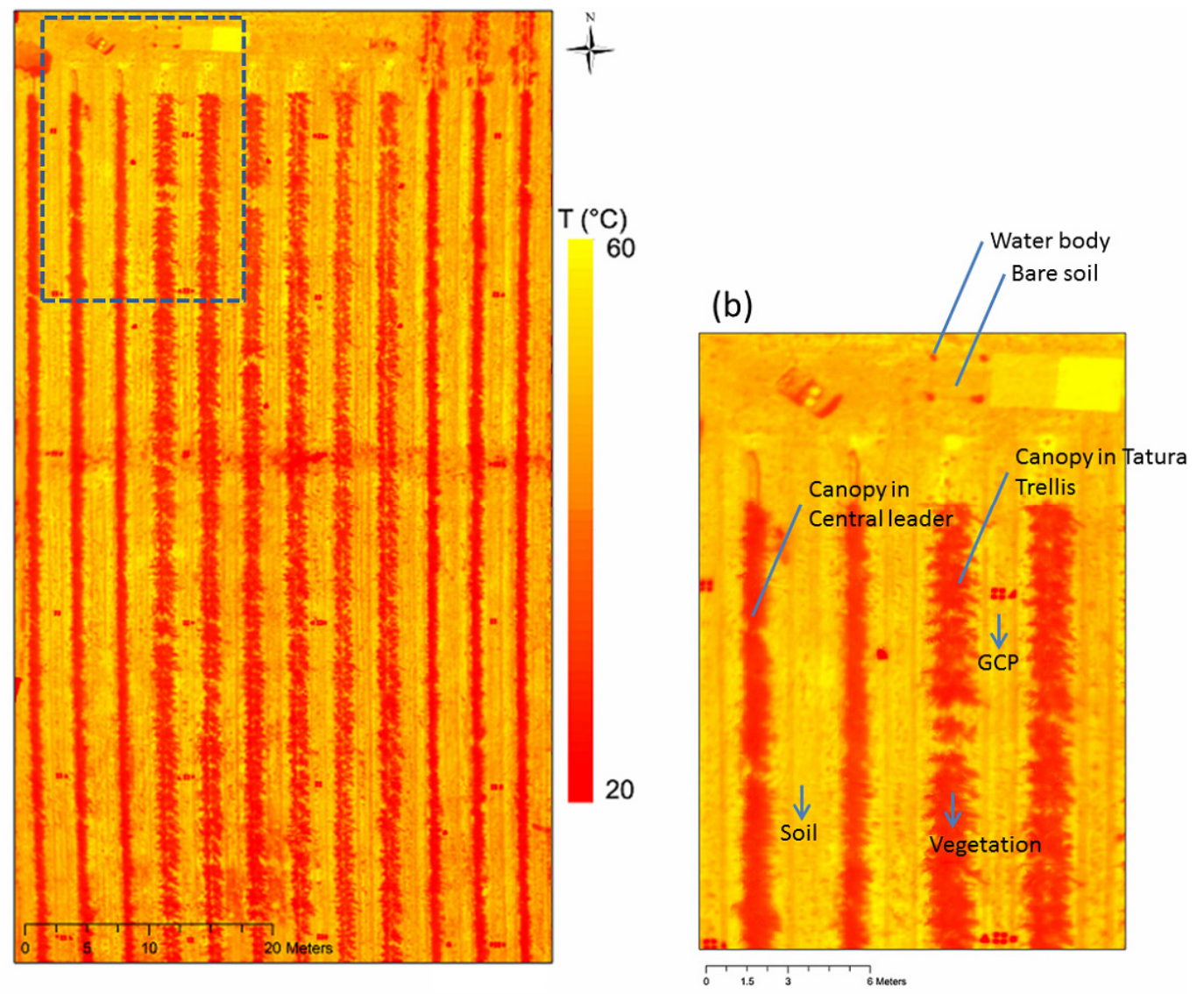

Figure 2. (a) Orthomosaic aerial TIR image across the orchard in temperature degree $\left(\mathrm{T}^{\circ} \mathrm{C}\right)$; (b) TIR image details of canopy training systems (Central Leader and Tatura Trellis), a shape of ground control point (GCP), and temperature differences in vegetation and soil. 


\section{RESULTS}

\subsection{Crop Water Stress Index (CWSI)}

CWSI was computed using canopy temperatures at centre canopy from the mosaicked image using the formula suggested by Jones (1992) in Eq. (3).

$$
C W S I=\frac{T_{\text {canopy }}-T_{w e t}}{T_{\text {dry }}-T_{w e t}}
$$

where $T_{\text {canopy }}$ is canopy temperature from the aerial TIR image, $T_{\text {wet }}$ the temperature of a fully transpiring leaf indication lower boundary, and $T_{d r y}$ the temperature of a non-transpiring leaf as upper boundary. Histogram analysis was used to estimate $T_{w e t}$, taken from the coldest temperature of the histogram from the orthomosaic TIR image (Rud et al., 2014). The histograms featured distinctive bimodal distribution, representing vegetation and soil background due to apparent temperature differences of the two features up to $30-35^{\circ} \mathrm{C}$. The second distribution in the bimodal was excluded, as the temperatures of the soil background were distributed across the second peak in the distribution. The upper boundary temperature, $T_{d r y}$, was determined by air temperature plus $6{ }^{\circ} \mathrm{C}$, based on the empirical methods as suggested by López et al. (2011). Figure 3 (a) shows the remotely estimated CWSI map from UAV, assessing the water status variability of the orchard. In Figure 3 (b), two water deficit and another two control treatment groups are presented. T1 - T4 represents sample trees from each treatment where SWP, $\mathrm{g}_{\mathrm{c}}$, and leaf temperature were measured to compare with CWSI. The higher CWSI was estimated in both water stressed groups, reaching 0.79 , whereas the CWSI in control groups was represented at values approximately to 0.39 . Figure 3 (c) shows the pixel level of CWSI based on $6.12 \mathrm{~cm}$ GSD which enables the exclusion of soil background to analyze canopy water status more precisely.

(a)

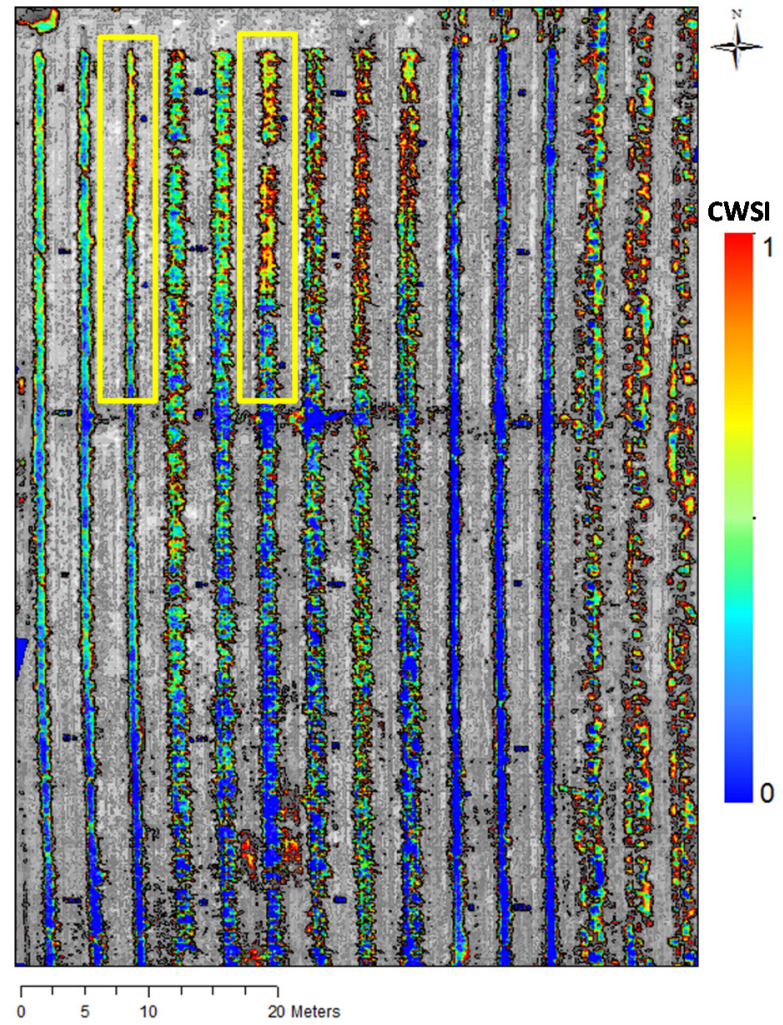

(b)

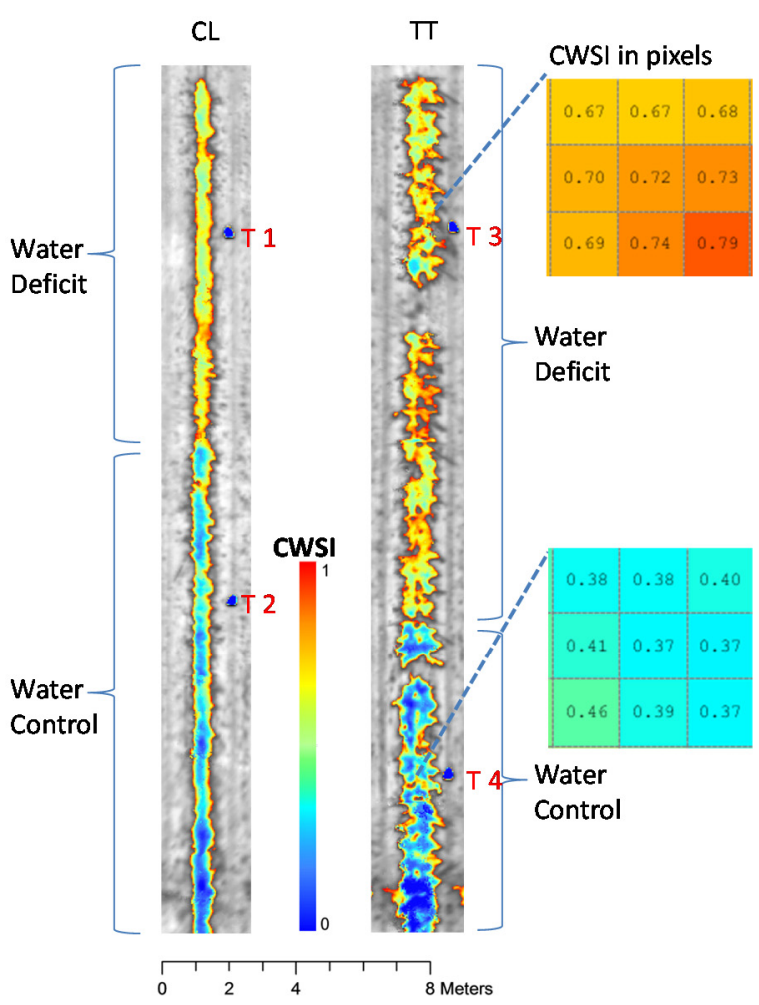

Figure 3. (a) CWSI map derived from UAV sensing. Two yellow rectangles present the area of irrigation treatments and sample trees; (b) CWSI of water deficit and control treatment groups in CL (Central Leader) and TT (Tatura Trellis); (c) Examples of the pixel level CWSI for T3 (in deficit) and T4 (in control) sample trees. 


\subsection{Analysis}

The ground measurements of midday SWP and $\mathrm{g}_{\mathrm{c}}$, which can directly reflect crop water stress parameters, were compared as shown in Figure 4 (a). Two measurements were moderately correlated with the coefficient of determination $\left(\mathrm{R}^{2}\right)$ of 0.86 . Both $\mathrm{T} 1$ and T3 in water deficit treatment indicated the lower SWP and $\mathrm{g}_{\mathrm{c}}$ than T2 and T4 in control treatment. CWSIs in the center of canopy, corresponding to the four sample trees, were taken along with the row direction in 27 pixels $(1.6 \mathrm{~m}$ length on ground) since each tree spacing was $1.0 \mathrm{~m}$ and $0.3 \mathrm{~m}$ extra length at two sides was considered as a buffer. The selected CWSI values were averaged in order to represent the water status of the sample trees. In Figure 4 (b) and 4 (c), the relationships between averaged CWSI and SWP, between averaged CWSI and $g_{c}$ are presented. The SWP measurements in the two treatments had high relationships with CWSI $\left(\mathrm{R}^{2}=0.92\right)$. Similar strong relationships between measured $g_{c}$ and transpiration rate and CWSI were also found $\left(\mathrm{R}^{2}=\right.$ 0.97).

\section{DISCUSSION AND CONCLUSIONS}

As shown in Table 1, T1 and T2, and $\mathrm{T} 3$ and $\mathrm{T} 4$ trees are from the same cultivar of nectarine and in the different training systems, central leader and Tatura trellis, respectively. For CWSI values, T2 showed relatively higher CWSI (0.50) than CWSI (0.36) from T4, although they were in the control treatment. Certainly, the CWSI value of $\mathrm{T} 2$ was lower than $\mathrm{T} 1$ (0.64), which is located in the same row and in deficit water treatment. A similar result was found for measured $g_{c}$. Although T2 was treated with normal irrigation, the actual water status appears to be under mild water stress conditions, according to both water status parameters of CWSI and $g_{c}$.

(a)

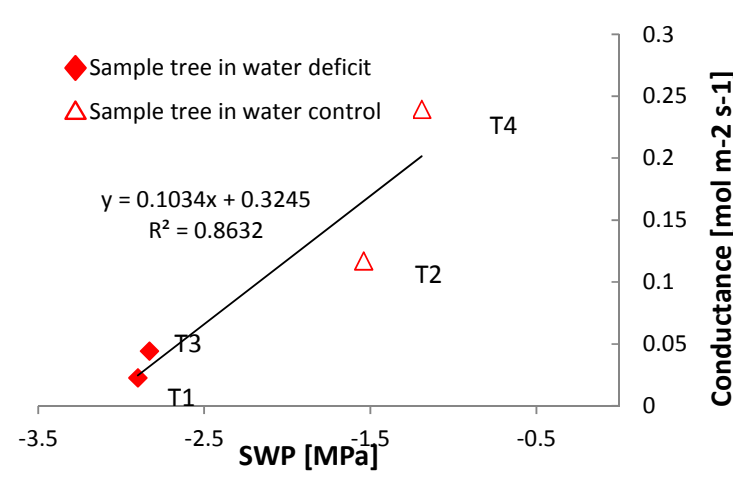

(b)

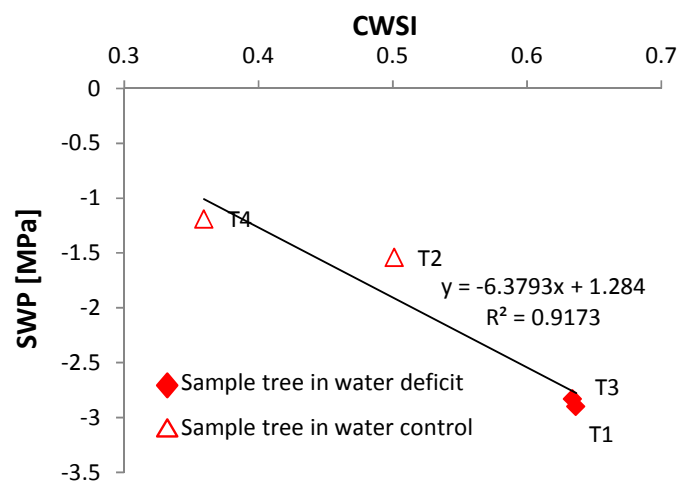

(c)

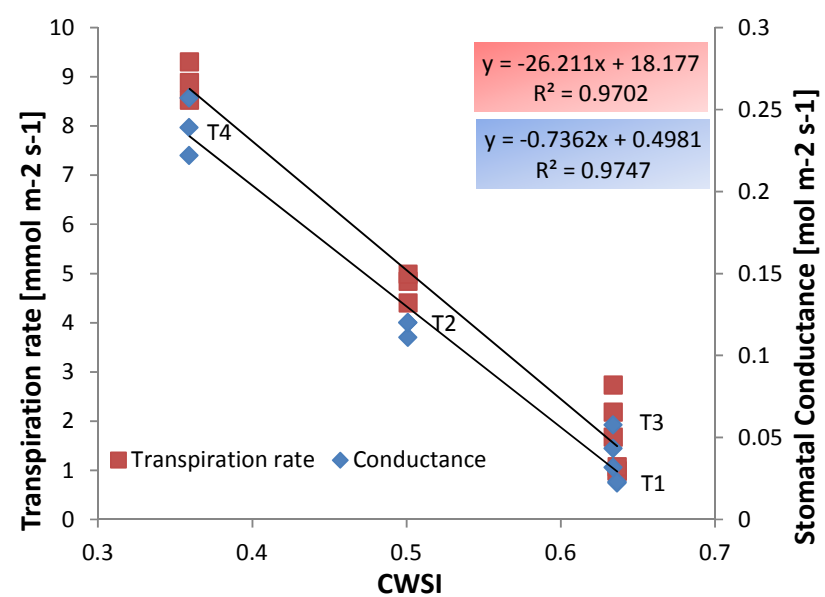

Figure 4. (a) Relationship between stem water potential (SWP) and stomatal conductance measured in the sample trees; (b) Relationships between CWSI and SWP; (c) Relationships between CWSI and stomatal conductance and transpiration rate.

This research demonstrated remotely estimated CWSI with reduced ground measurements and efficiency in the calculation for field scale estimation based on the histogram analysis, not requiring an artificial wet surface as a reference. CWSI map was generated to assess spatial variability of water stress across the entire nectarine orchard using high-resolution TIR images from a UAV platform. The remotely estimated CWSI was highly correlated with midday SWP and $\mathrm{g}_{\mathrm{c}}$, which can be used as crop water status 
Park et al., Estimation of crop water stress using high-resolution imagery from UAV

parameters. This shows that the CWSI can be remotely and accurately estimated from UAV-borne imagery. In addition, the CWSI map can be used a location-based determination factor of irrigation needs.

For future studies, the relationships between canopy temperature and crop cultivar, or canopy structure will be considered. Adaptive decision of the lower boundary temperature will be further studied based on a rowbased approach.

\section{ACKNOWLEDGMENTS}

This research was supported by the Innovation Seed Fund for Horticulture Development grant from the University of Melbourne and Department of Economic Development, Jobs, Transport and Resources, Victoria and ARC LIEF grant (LE130100040).

\section{REFERENCES}

Bellvert, J., Zarco-Tejada, P., Girona, J. and Fereres, E. (2014) Mapping crop water stress index in a 'Pinotnoir' vineyard: comparing ground measurements with thermal remote sensing imagery from an unmanned aerial vehicle. Precision Agriculture, 15, 361-376.

Berni, J. A. J., Zarco-Tejada, P. J., Sepulcre-Cantó, G., Fereres, E. and Villalobos, F. (2009) Mapping canopy conductance and CWSI in olive orchards using high resolution thermal remote sensing imagery. Remote Sensing of Environment, 113, 2380-2388.

FLIRSystems (2013) User's manual FLIR Ax5 series. FLIR Systems.

Fuentes, S., Bei, R., Pech, J. and Tyerman, S. (2012) Computational water stress indices obtained from thermal image analysis of grapevine canopies. Irrigation Science, 30, 523-536.

Gao, B. C. (1996) NDWI - A normalized difference water index for remote sensing of vegetation liquid water from space. Remote Sensing of Environment, 58, 257-266.

Jackson, R. D., Idso, S. B., Reginato, R. J. and Pinter, P. J., Jr. (1981) Canopy temperature as a crop water stress indicator Wheat. Water Resources Research (USA).

Jones, H. G. (1992) Plants and microclimate : a quantitative approach to environmental plant physiology, Cambridge [England] ; New York, NY, USA : Cambridge University Press, 1992.

2nd ed.

Kim, Y., Glenn, D. M., Park, J., Ngugi, H. K. and Lehman, B. L. (2011) Hyperspectral image analysis for water stress detection of apple trees. Computers and Electronics in Agriculture, 77, 155-160.

Leinonen, I. and Jones, H. G. (2004) Combining thermal and visible imagery for estimating canopy temperature and identifying plant stress. Vol. 55 Oxford University Press, pp. 1423-1431.

López, R. L.-., Ramírez, R. A., Sánchez-Cohen, I., Bustamante, W. O. and González-Lauck, V. (2011) Evapotranspiration and Crop Water Stress Index in Mexican Husk Tomatoes (Physalis ixocarpa Brot). InTech.

Meron, M., Tsipris, J., Orlov, V., Alchanatis, V. and Cohen, Y. (2010) Crop water stress mapping for sitespecific irrigation by thermal imagery and artificial reference surfaces. Precision agriculture, 11, 148-162.

Möller, M., Alchanatis, V., Cohen, Y., Meron, M., Tsipris, J., Naor, A., Ostrovsky, V., Sprintsin, M. and Cohen, S. (2007) Use of thermal and visible imagery for estimating crop water status of irrigated grapevine. Vol. 58 Oxford University Press, pp. 827-838.

Moran, M. S., Clarke, T. R., Inoue, Y. and Vidal, A. (1994) Estimating crop water deficit using the relation between surface-air temperature and spectral vegetation index. Remote sensing of environment (USA), 49, 246-263.

Rud, R., Cohen, Y., Alchanatis, V., Levi, A., Brikman, R., Shenderey, C., Heuer, B., Markovitch, T., Dar, Z., Rosen, C., Mulla, D. and Nigon, T. (2014) Crop water stress index derived from multi-year ground and aerial thermal images as an indicator of potato water status. Precision Agriculture, 15, 273-289.

Zarco-Tejada, P. J., González-Dugo, V. and Berni, J. A. J. (2012) Fluorescence, temperature and narrowband indices acquired from a UAV platform for water stress detection using a micro-hyperspectral imager and a thermal camera. Remote Sensing of Environment, 117, 322-337. 